\title{
Mid-term (2009-2019) demographic dynamics of young beech forest in Albongbunji Basin, Ulleungdo, South Korea
}

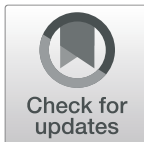

Cho Yong-Chan ${ }^{1 *} \mathbb{D}$, Sim Hyung Seok ${ }^{1,2}$, Jung Songhie ${ }^{1}$, Kim Han-Gyeoul ${ }^{1}$, Kim Jun-Soo ${ }^{3}$ and Bae Kwan-Ho ${ }^{4}$

\begin{abstract}
Background: The stem exclusion stage is a stage of forest development that is important for understanding the subsequent understory reinitiation stage and maturation stage during which horizontal heterogeneity is formed. Over the past 11 years (2009-2019), we observed a deciduous broad-leaved forest in the Albongbunji Basin in Ulleungdo, South Korea in its stem exclusion stage, where Fagus engleriana (Engler's beech) is the dominant species, thereby analyzing the changes in the structure (density and size distributions), function (biomass and species richness), and demographics.

Results: The mean stem density data presented a bell-shaped curve with initially increasing, peaking, and subsequently decreasing trends in stem density over time, and the mean biomass data showed a sigmoidal pattern indicating that the rate of biomass accumulation slowed over time. Changes in the density and biomass of Fagus engleriana showed a similar trend to the changes in density and biomass at the community level, which is indicative of the strong influence of this species on the changing patterns of forest structure and function. Around 2015, a shift between recruitment and mortality rates was observed. Deterministic processes were the predominant cause of tree mortality in our study; however, soil deposition that began in 2017 in some of the quadrats resulted in an increase in the contribution of stochastic processes (15\% in 2019) to tree mortality. The development of horizontal heterogeneity was observed in forest gaps.

Conclusions: Our observations showed a dramatic shift between the recruitment and mortality rates in the stem exclusion stage, and that disturbance increases the uncertainty in forest development increases. The minor changes in species composition are likely linked to regional species pool and the limited role of the life-history strategy of species such as shade tolerance and habitat affinity. Our midterm records of ecological succession exhibited detailed demographic dynamics and contributed to the improvement of an ecological perspective in the stem exclusion stage.
\end{abstract}

Keywords: Demographic dynamics, Fagus engleriana, Oceanic island, Stem exclusion stage, Forest succession, Forest dynamics

\footnotetext{
* Correspondence: bz0288@korea.kr

${ }^{1}$ Conservation Center for Gwangneung Forest, Korea National Arboretum, Pocheon 11186, South Korea

Full list of author information is available at the end of the article
}

(c) The Author(s). 2020 Open Access This article is licensed under a Creative Commons Attribution 4.0 International License, which permits use, sharing, adaptation, distribution and reproduction in any medium or format, as long as you give appropriate credit to the original author(s) and the source, provide a link to the Creative Commons licence, and indicate if changes were made. The images or other third party material in this article are included in the article's Creative Commons licence, unless indicated otherwise in a credit line to the material. If material is not included in the article's Creative Commons licence and your intended use is not permitted by statutory regulation or exceeds the permitted use, you will need to obtain permission directly from the copyright holder. To view a copy of this licence, visit http://creativecommons.org/licenses/by/4.0/. 


\section{Background}

Monitoring the process of changes in species composition and structure during forest successional development is key to understanding changes in ecosystem function (Noss 1990; Condit 1995; Hobbie 2003; Spellerberg 2005; Lutz and Halpern 2006; Cheon et al. 2014; Ediriweera et al. 2020). The importance of understanding forest dynamics in conserving and managing natural resources has been widely recognized (Gitzen et al. 2012; Sergeant et al. 2012; Chun and Lee 2019). Tree communities in forests contain most of the ecosystem's carbon stock, and changes in tree community composition with forest development are key determinants of understory biodiversity (Franklin et al. 2002; Lutz and Halpern 2006). In particular, the process of tree community development after anthropogenic or natural disturbance is a spatiotemporal laboratory essential for a clear understanding of key ecological processes and stages, which provides ecological knowledge necessary for species and forest restoration and management (Franklin et al. 2002; Lutz and Halpern 2006; Heiri et al. 2009; Halpern and Lutz 2013). The stem exclusion stage (Oliver 1981), during which a rapid increase in biomass, a competitioninduced decrease in stem density, and density-dependent tree mortality are typically observed along with the growth of tree communities, is an important stage for understanding the subsequent understory regeneration stage and the maturation stage in which horizontal heterogeneity is formed.

The species composition of local communities at ecological time scales is influenced by deterministic and stochastic processes (Vellend 2010). The deterministic process leads to convergent community structure (with a lower spatial variation in species assembly) (Hubbell 2001), whereas stochastic processes lead to a divergent community structure (with a higher spatial variation in species assembly) (Chase and Myers 2011). Researchers have reached an important consensus that both ecological processes operate concurrently and their relative importance is generally affected by the environmental context and the state of community development (e.g., forest age) (Franklin et al. 2002; Lutz and Halpern 2006; Halpern and Lutz 2013). For example, the stem exclusion stage in forest development is dominated by deterministic processes such as resource competition among species and density-dependent tree mortality (Heiri et al. 2009). In later forest development stages, the effects of stochastic processes on horizontal diversity increase, for example, the role of forest gaps in increasing forest diversity becomes more apparent, and these gaps result from disturbances that are difficult to predict (e.g., wind and many diseases and insects) (Franklin et al. 2002). Since various forest development models were constructed by contemporaneously observing and connecting specific stages (i.e., using a chronosequence approach) instead of by observing forest development over long time periods, various empirical approaches are required to understand the relative changes in these important processes.

Demographic dynamics, resulting from recruitment, growth, and death in a tree community, are a lengthy process (Lima et al. 2016). This temporal challenge affects the measurement frequency, which is important for understanding the occurrence of key events, including disturbances and subsequent changes, and the related ecological impacts. In most ecosystems, studies on the dynamics of tree communities, especially the spatiotemporal variations of mortality events, have been limited due to the long lifespan of trees and stochastic deaths caused by unpredictable events (Lutz and Halpern 2006). Given that most studies apply a regular measurement interval (e.g., every five or ten years) depending on scale, budget, and personnel availability, micro-level forest development processes are rarely observed. For instance, there are only limited reports on tree demographic dynamics as well as recruitment and death rates. In the stem exclusion stage of beech (Fagus spp.) forests, in particular, there are hardly any micro-level observations of recruitment and mortality rate fluctuations and the ensuing changes in the size distribution of individuals (from a bell-shaped to an inverted J-shaped curve) (Heiri et al. 2009). The stem exclusion stage is a stage of forest development important for understanding the patterns of change in tree demographic rates, especially regarding density and its subsequent effects on forest functions (e.g., biomass and diversity) (Moridi et al. 2015).

Interestingly, deciduous broad-leaved forest stands dominated by Fagus engleriana are widely distributed

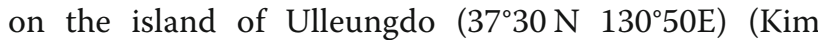
et al. 1986; Kim 1988; Cho et al. 1993), which exists in a maritime climate and is distant from southern China, the regional center of continental climate and distribution of Fagus engleriana (Fang and Lechowicz 2006). In East Asia, with the exception of the Japanese archipelago, Fagus spp. (e.g., Fagus longipetiolata, Fagus lucida, and Fagus engleriana) are distributed mainly in the temperate vegetation climate zone that spans from the warm (including subtropical) areas, basically south of $34^{\circ} \mathrm{N}$ to the cool, monsoon-influenced areas to the north (up to $55^{\circ} \mathrm{N}$ ) (Fang and Lechowicz 2006; Guo and Werger 2010).

Most of the studies on forests dominated by Fagus spp. have examined the gap regeneration stage (e.g., (Glatthorn et al. 2018) and have been conducted in mountainous habitats. However, in the Albongbunji Basin within Nari Caldera Ulleungdo, which is flat, 
there are Fagus engleriana-dominated forests where secondary succession is underway. Nari Caldera has two alluvial plains, Naribunji Basin and Albongbunji Basin (Park 1997) which had been covered by forest stands until the late 19th century (Jeong 2006). With the settlement of a large population after the early 20th century, the forests began to shrink as more agricultural land was needed for crop cultivation and cattle grazing (Rii 2012). Currently, agricultural use is prohibited in the Albongbunji Basin, and a young forest dominated by Fagus engleriana is regenerating and a large grassland is also present. Fagus engleriana usually grows on slopes in a multi-stemmed form (Peters 1992; Cao et al. 1995). In contrast, the young individuals of the Fagus engleriana-dominated forest in the alluvial plain on Ulleungdo are single-stem trees. This is ecologically significant in understanding the process of development of a Fagus englerianadominated forest as well as the development of species architecture.

From 2009 to 2019, we performed annual monitoring of the development process of a Fagus engleriana-dominated young deciduous broad-leaved forest. The main focus of this study is on the changes in forest development in the stem exclusion stage, which can be summarized into three points: (1) changing patterns of structural and functional aspects; (2) demographic rates of a tree population including its recruitment and mortality rates, and (3) characteristics associated with forest development models.

\section{Results}

\section{Initial community structure and light environment}

The age structure of the community showed a mixed structure in which there were older trees present that had survived livestock grazing (e.g., Celtis jessoensis) and younger trees recruited after the grazing ban. The age distribution in 2009 showed a bell-shaped curve (Fig. 1). Canopy openness was $10.7 \pm 2.7 \%$ (Fig. 1), about half the level for mainland mature deciduous forests ( 20\%) (Cho et al. 2020).

In 2009, the mean age of the tree species was $39.0 \pm$ 12.9, ranging from 10 years (Fagus engleriana) to 81 years (Celtis jessoensis). Among the tree species with at least 30 individuals, Celtis jessoensis had the highest mean age ( $41.4 \pm 13.4$ years, $n=33)$, followed by Acer pictum var. mono $(39.4 \pm 10.6$ years, $n=39)$, Fagus engleriana (38.3 \pm 13.5 years, $n=133)$, and Cornus controversa $(36.3 \pm 10.6$ years, $n=33)$. Even though the growth rate necessary to reach the size that allows for increment core extraction may differ from species to species, most of the species examined were those preferring disturbed areas and that were recruited in similar periods.

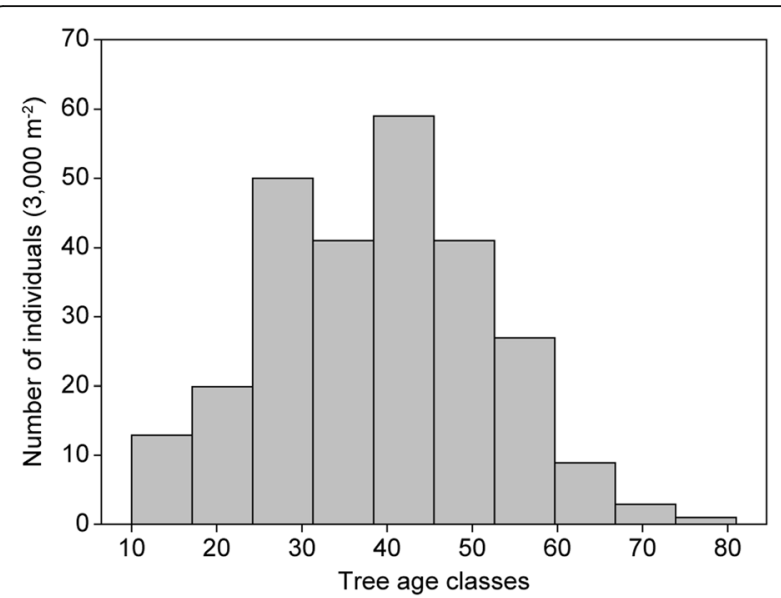

Fig. $1 \mathrm{~A}$ bell-shaped age distribution of the population of the constituent species based on the 264 increment cores of growth rings collected from the 20 quadrats installed in 2009 in Albongbunji Basin in Ulleungdo

\section{Changes in community structure, function, and environment}

The mean stem density showed a bell-shaped curve over time, with stem densities constantly increasing from 2009 (when measurement began), peaking in 2014 (midterm), and then constantly declining through 2019 (when measurement ended) (Fig. 2a). The mean biomass (Fig. 2b) rapidly increased to its peak in 2016 and fell sharply after that. Compared to the initial value, the mean biomass increased by $45 \%$ in 11 years. BHA constantly increased from the initial measurement until the end of our measurements (Fig. 2c) (Cho et al. 2020).

The DBH distribution increasingly took the shape of the exponential distribution (decrease in the value of the shape parameter) as the stem density increased and changed to the shape of the normal distribution starting in 2015 when stem density began to decline (Fig. 3a and Supplementary File 1). The scale parameter constantly increased along with the increase in the shape parameter after a slight decrease after the initial measurement, which caused the periphery to lengthen and the distribution graph peak to decrease. The diameter class distribution changed from a multi-peak to a single-peak bell shape, starting in 2016 (Supplementary file 1). The changes in the two parameters of biomass distribution showed a tendency similar to that of diameter size distribution, whereby the distribution of biomass classes rapidly developed from a single peak to a multi-peak shape (Fig. $3 \mathrm{~b}$ and Supplementary file 1).

Among the tree species measured, the patterns of change in mean density and mean biomass varied from species to species (Fig. 4a and b). While the variation in mean biomass among different species was high, the mean stem density uniformly decreased in all species 

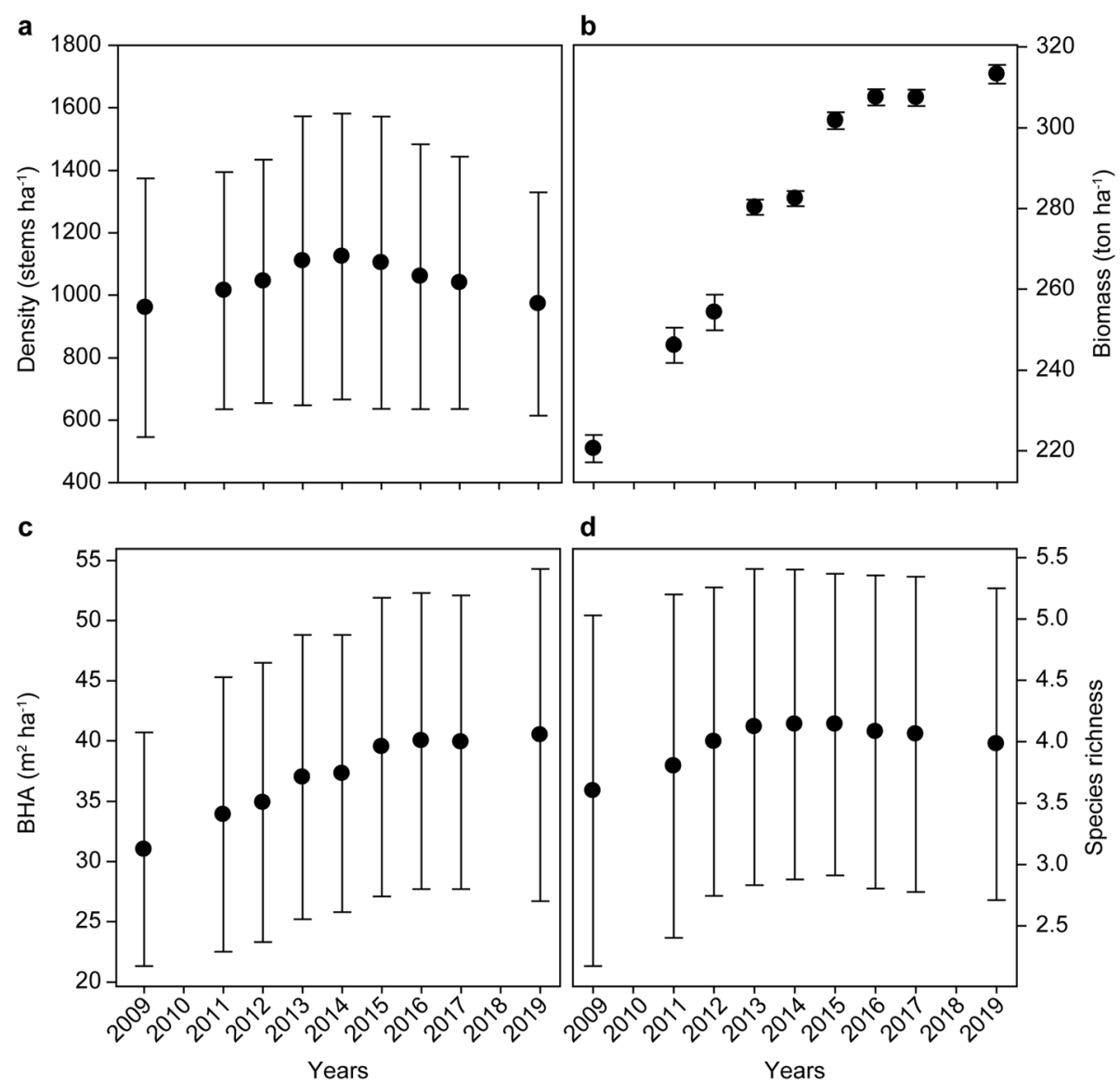

Fig. 2 Changes over 11 years (2009-2019) in the structure and species diversity of the young deciduous broad-leaved forest in Albongbunji Basin/Ulleungdo. No measurements were made in 2010 and 2018 was excluded from analysis due to data loss

after 2015, albeit to a greater or lesser extent among different species. The density and biomass changes of the dominant species, Fagus engleriana, were similar to those measured at the community level, thus verifying its strong influence on the community-level dynamics. The density and biomass of the second dominant species Celtis jessoensis fluctuated slightly, increasing in some years and slightly decreasing in others. The stem density of Acer pictum var. mono steadily decreased following its initial measurement, and its biomass decreased after the midterm, indicating it had a limited recruitment status. As succession advanced, the stem density of the shadetolerant species Tilia amurensis was expected to increase, but it remained unchanged or even decreased. However, it showed a slow increase in biomass along with individuals' growth.

The soil exposure rate (\%) of the forest floor maintained its initial level $(\leq 2 \%)$ from 2009 to 2016, without any significant deviation (Fig. 5). Starting in 2017, however, soil deposition sharply increased to $12 \%$ in 2019 , as did the deviation, resulting in an increase in variation at the quadrat level.

\section{Changes in demographic rates}

A total of 81 trees were recorded to have perished during the 11-year measurement period. The tree population growth rate showed the same value as the recruitment rate until 2014 because stem mortality was not recorded until 2014 (Fig. 6). The tree population growth rate increased from $2.0 \%$ in 2011 to $3.9 \%$ in 2012, then continuously decreased until 2014, and fluctuated from 2015 onwards, showing negative values after 2015, in which stem density began to decrease.

Stem mortality increased from 0.0 to $1.8 \%$ in 2015 , peaked at $3.9 \%$ in 2016, and subsequently decreased and fluctuated. In contrast, the recruitment rate increased from $2.0 \%$ in 2011 and peaked at 3.9\% in 2012, followed by a steady decrease, converging towards $0.0 \%$ in 2015 , in which stem death began to be observed. The recruitment rate and the mortality rate were significantly negatively correlated $(r=-0.758, p=0.029)(n=8)$.

Starting in 2015, when stem mortality was first recorded, most mortality events occurred in trees with smaller DBH $(\leq 20 \mathrm{~cm}, 82.7 \%)$ and in Fagus engleriana (63.0\% of total mortality) (Fig. 7a). However, larger 


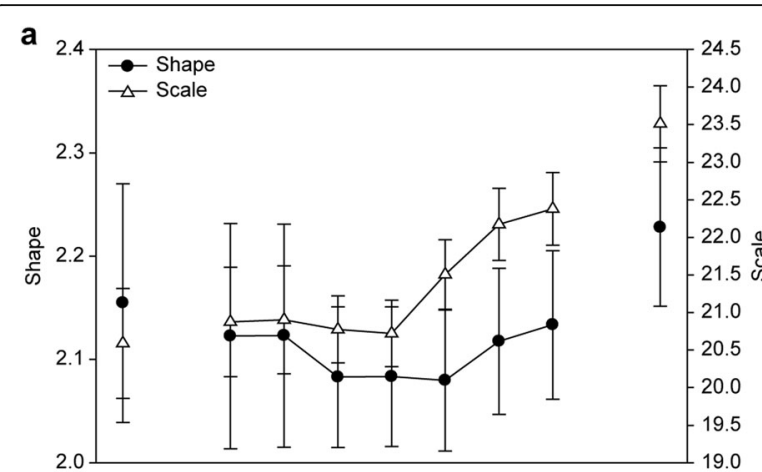

b

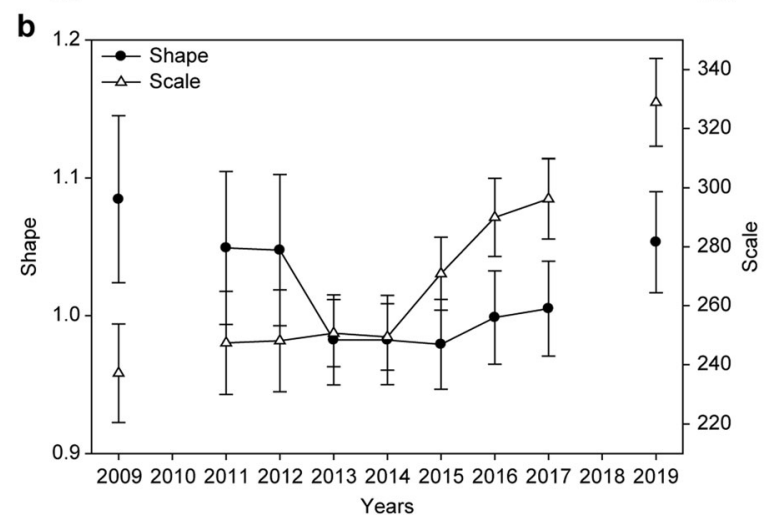

Fig. 3 Changes (2009-2019) in the distribution shape and scale parameters of the diameter at breast height (DBH) (a) and biomass (b) of the tree communities measured in Albongbunji Basin in Ulleungdo. The main inflection point follows the point at which the decrease in stem density begins. The DBH and biomass are size variables of the constituent factors in the community and change in line with structural changes

individuals (Tilia amurensis, Fagus engleriana, and Celtis jessoensis) were also included among mortality events. The diameter class distribution of dead trees showed the right skewed-distribution (Fig. 7b).

An important change in ecological processes was observed between 2015, in which tree mortality was first observed, and 2019 (Fig. 8). Suppression was the only cause of death in 2015 and 2016, that is, deterministic processes were predominant. In the later phase of the survey, however, stem deaths due to soil deposition occurred, increasing the percentage of tree mortality attributed to stochastic processes (16.7\% in 2017 and $31.4 \%$ in 2019). A number of forest gaps were formed due to stem deaths of large trees such as Prunus takesimensis (see Fig. 9 and Supplementary File 2). The standing dead trees in the canopy layer were categorized as "suppression" as the cause of death because there was no evidence of other causes of mortality (e.g., pathogens). The dead trees in a quadrat exposed to soil deposition disturbance were recorded as "soil deposition," irrespective of their size.

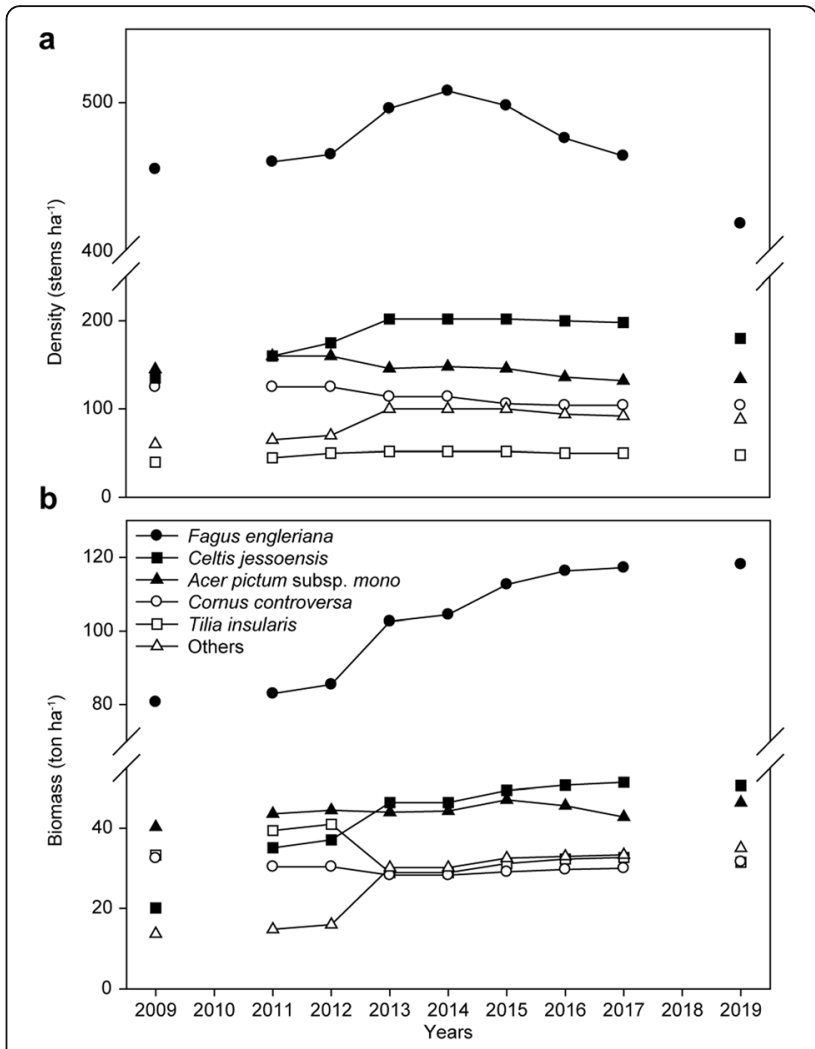

Fig. 4 Changes (2009-2019) in the mean stem density (a) and biomass (b) for each constituent tree species in Albongbunji Basin/ Ulleungdo. The standard deviations were omitted for visual convenience

Changes in species diversity and turnover rate

During the observation period, the mean species richness was relatively low, ranging from 3.6 to 4.1 species (fluctuation range: $\leq 0.5$ species). After 2016 and the beginning of stem death, richness did not significantly change (Fig. 2d). The species turnover rate was initially high and peaked early in the course of our observations

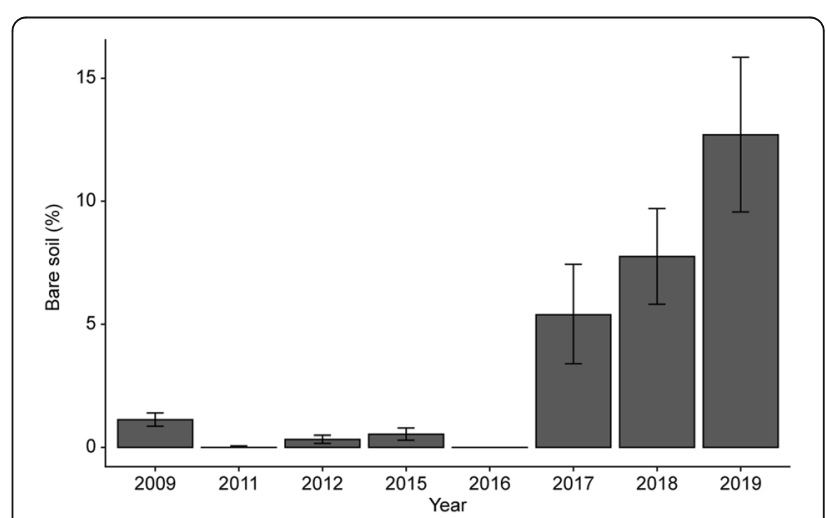

Fig. 5 Changes (2009-2019) in the mineral soil exposure rate (\%) measured at the forest floor in Albongbunji Basin/Ulleungdo. From 2017 onwards, soil deposition by heavy rains greatly changed the forest floor environment, increasing spatial heterogeneity 


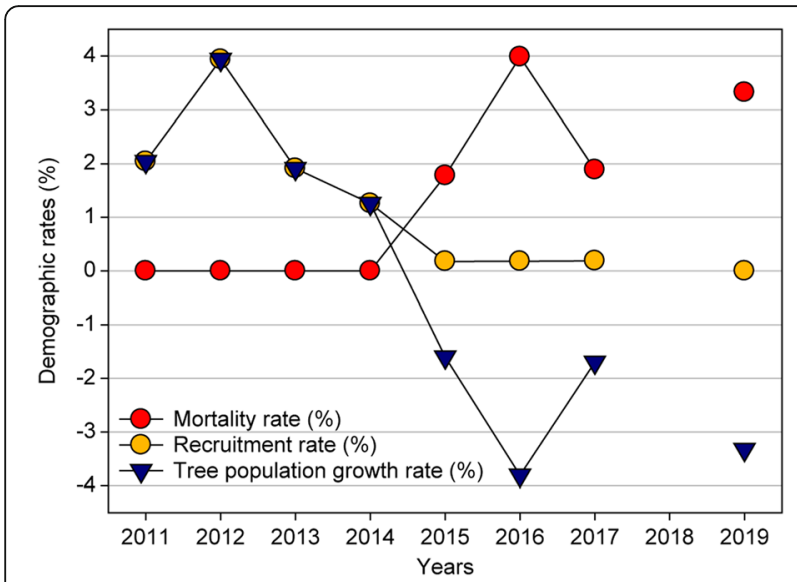

Fig. 6 Changes (2009-2019) in the demographic rates (rates of recruitment, mortality, and population growth) in tree communities in Albongbunji Basin/Ulleungdo

(i.e., in 2012), after which time, it dramatically decreased and remained relatively low for the remainder of our study (Fig. 10). The initial increase in the turnover rate occurred immediately before the onset of a decrease in stem density, resulting in subsequently low species turnover rates $(0.0 \%$ in 2013 and $0.3 \%$ in 2014).

A total of 12 tree species were recorded at the survey site; these included ten deciduous broad-leaved species (Fagus engleriana, Acer pictum var. mono, Ulmus laciniata, Acer takesimense, Prunus takesimensis, Tilia amurensis, Cornus controversa, Celtis jessoensis, Phellodendron amurense, and Styrax obassia) and two evergreen coniferous trees (Tsuga ulleungensis and Taxus cuspidata).

\section{Discussion}

\section{Structural and functional forest dynamics}

Fagus engleriana distributed in China is reported to be rapidly regenerating plants with a high shade tolerance that grows in hilly forest gaps (Zhang et al. 2017). However, given that the giant Fagus engleriana trees dominating the forest vegetation on Ulleungdo, which is frequently exposed to typhoon disturbance, have practically zero mortality ( $0.0 \%$ from 2013 to 2019 ) (Cho et al. 2020), the majority of research on the Fagus engleriana forest on Ulleungdo has focused on its structure and species composition rather than on its regeneration. As previously mentioned, the forest in the survey site in Albongbunji Basin is a forest in the stem exclusion stage with high tree density and an underdeveloped understory tree layer. According to the development stages defined for Fagus sylvatica-dominated forests (Heiri et al. 2009), it belongs to the closed forest stage. Fagus engleriana is known to be a multi-stemmed tree in all other growing environments (Peters 1992), but all individuals in the survey site are single-stemmed trees, which indicates that these trees relatively young and have been regenerated from limited human utilization such as coppicing. The evidence of secondary succession currently taking place in the survey site is based on four observational findings: (1) stumps of perished trees over a large area and quasi-absence of multi-stemmed trees resulting from stem cutting, (2) bell-shaped tree community age structure (see the "Results" section), (3) stem density of the tree species, and (4) overall landscape and ecosystem context on Ulleungdo.

From 2015 onward, along with a decrease in stem density, the rates at which BHA and biomass accumulated tended to decrease (Fig. 2). Biomass accumulation is known to follow a sigmoidal curve over a long period of time (Barnes et al. 1998). The biomass of the forest dominated by giant Fagus engleriana (DBH class of $70 \mathrm{~cm}$ ) on the slope adjacent to the study site is 368.7 ton ha $\mathrm{ha}^{-1}$ as of 2019 , showing a slow biomass accumulation (Cho et al. 2020). Considering the size of individual trees and average age, a continuous increase in biomass can be expected in the study site unless fatal disturbances occur. Having said that, the continuous soil deposition disturbance and gap formation events in the study area may contribute to enhancing the heterogeneity of forest structure, but this will likely induce changes in biomass by increasing the tree mortality rate. Meanwhile, changes in tree community structure and function over 11 years were found to be largely attributed to changes in stem density and biomass of the dominant species, Fagus engleriana (Figs. 2 and 3).

The effect of the population growth rate, ranging from positive to negative values, on the size (DBH and biomass) distribution patterns of the tree community was observed (Fig. 6). Tree size distribution in a forest is an attribute pertaining to demographic rates that can be estimated from tree growth, death, and recruitment processes (Coomes and Allen 2007). In the period prior to 2015 , only recruitment occurred, and no tree mortality was observed. This increased the population size of the smaller size classes, leading to right-skewed tree size distributions. After 2015, the opposite occurred; there were few to no recruited individuals, and more small individuals dying than larger ones, leading to post-2015 shape parameters with a reduced right-skewed distribution (see Supplementary File 1). Unlike the shape parameter changes, the values of the scale parameters towards DBH and biomass distributions showed a steady increase despite the occurrence of a slight decrease. Scale parameters are associated with measurement ranges (here, the minimum and maximum DBH values). With the growth of constituent individuals increasing the right-skewed range of the size distributions, the scale parameter also continued to grow. 

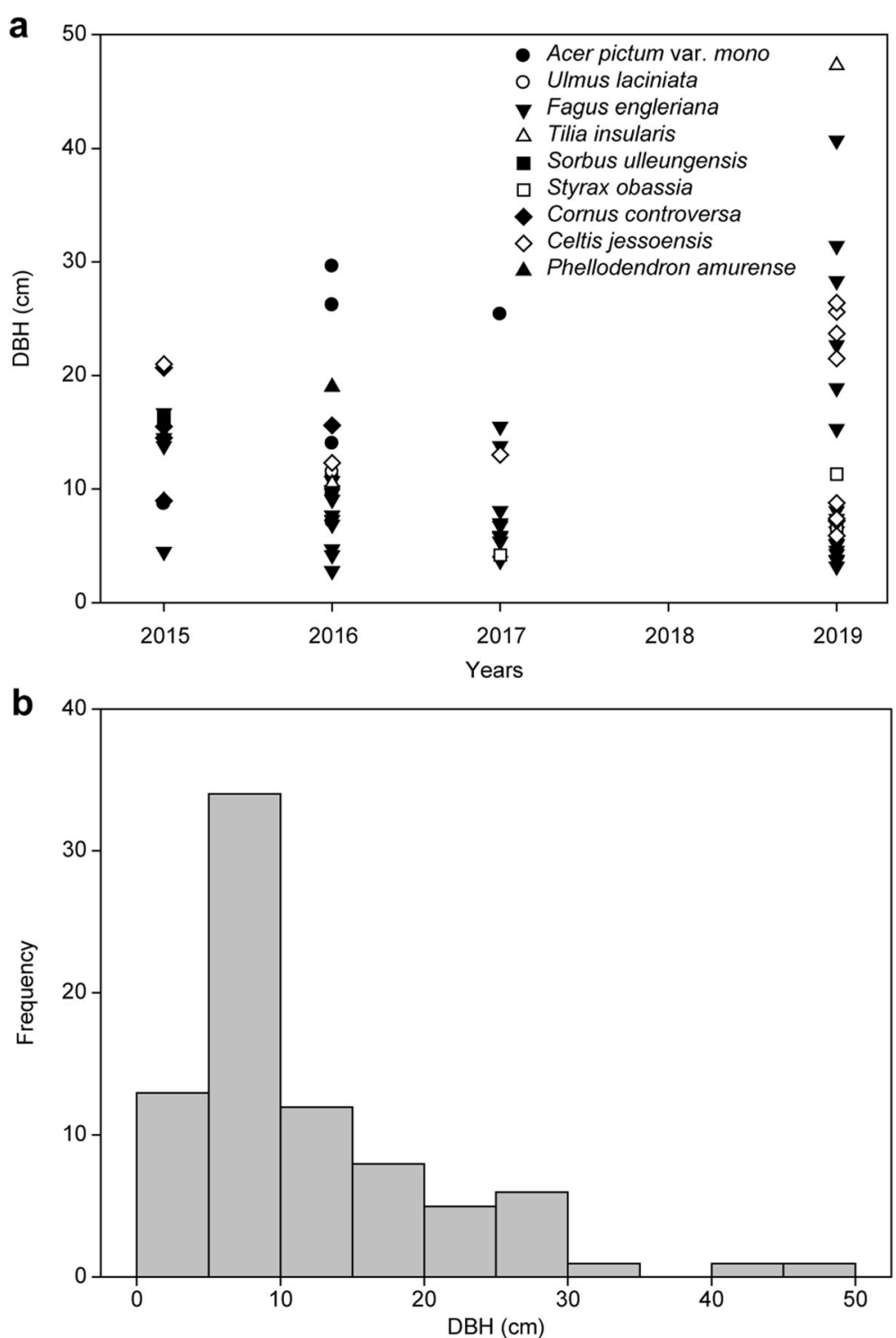

Fig. $7 \mathrm{DBH}$ ranges of the dead species (a) and DBH distribution of the dead stems (b) in Albongbunji Basin/Ulleungdo

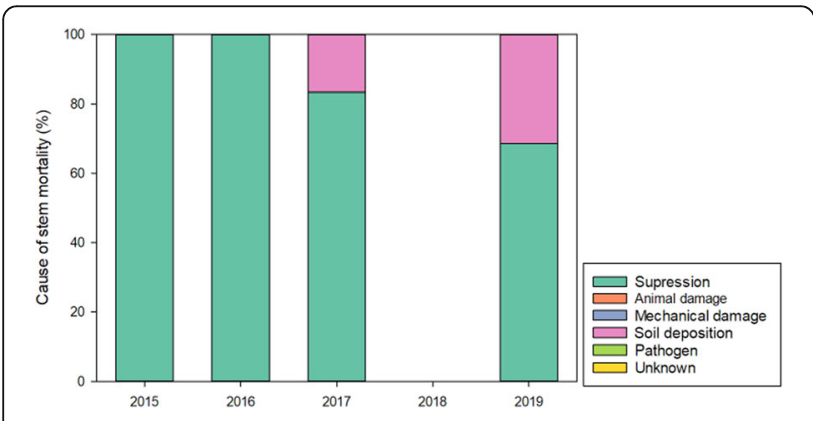

Fig. 8 Changes (2015-2019) in the causes of tree death observed in Albongbunji Basin/Ulleungdo. Suppression and animal damage (herbivory) were evaluated as deterministic processes and mechanical damage, slope failure/soil deposition, and pathogens as stochastic processes
Little change was observed in species richness during the observation period. The species turnover rate also showed relatively low values $(0-5.9 \%)$ (Fig. 10). This implies that most of the potential species capable of establishing in the study area were observed in the initial measurements. Seedlings observed on the forest floor during the observation period belonged to the same species as the existing adult trees, and no other species were observed among the seedlings. Moreover, a total of 12 tree species occurred in the study site, whose species composition was similar to that of most deciduous broad-leaved Fagus engleriana-dominated forests occurring on the slopes of Ulleundo, regardless of life-history traits such as shade tolerance (Kim et al. 1986; Kim 1988; Cho et al. 1993; Lee et al. 2006). Ulleungdo is 


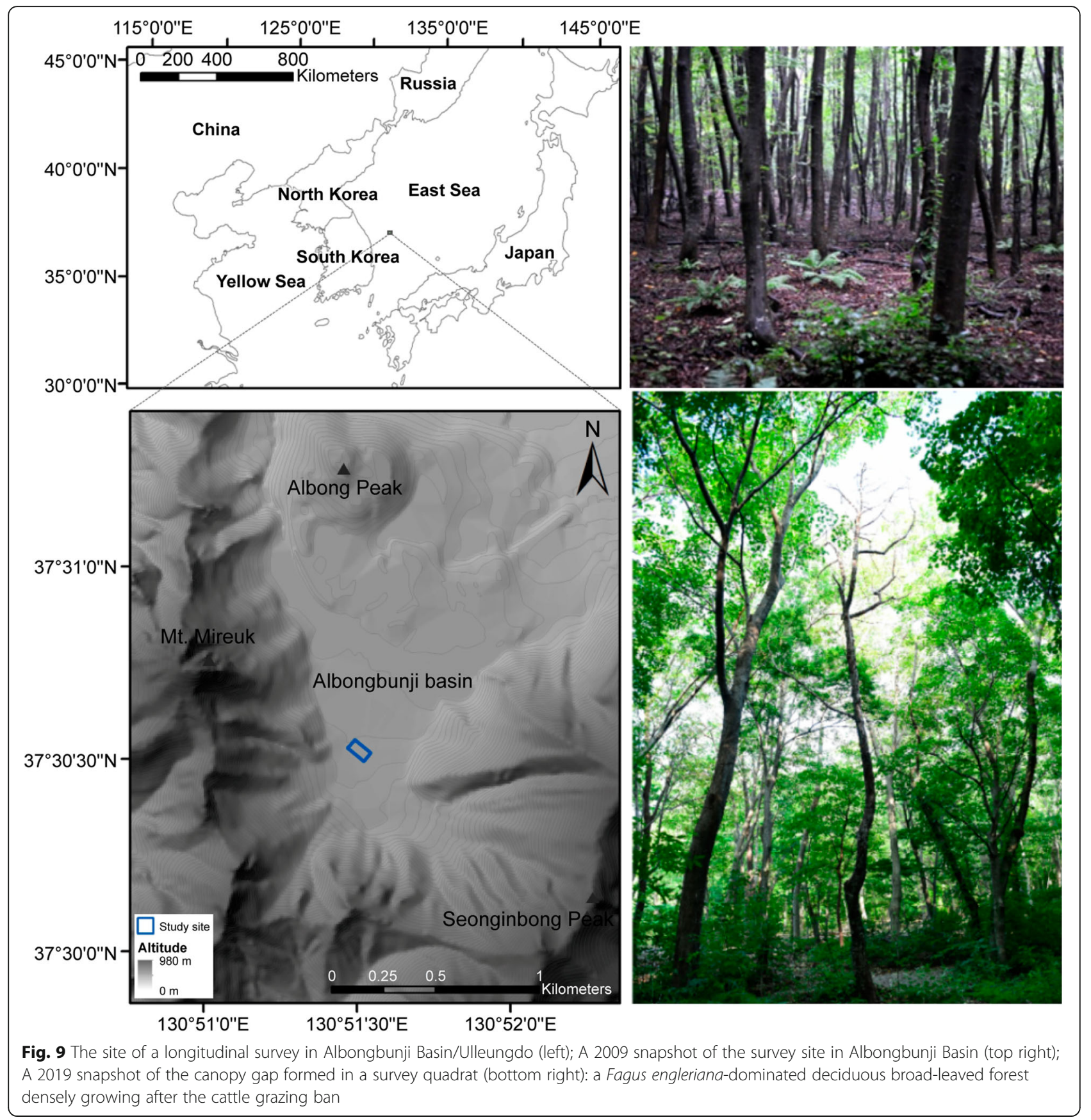

frequently hit by typhoons accompanied by strong winds and heavy rainfall, which may constitute a background for the coexistence of tree species with different lifehistory strategies. The low species turnover rate measured is also associated with the pattern of low diversity change. In general, temperate forests have lower turnover rates than tropical forests (Stephenson and Mantgem 2005), and the high turnover rate in tropical forests is known to contribute to their high tree diversity (Phillips et al. 1994). Furthermore, differential mortality of species with various traits (e.g., shade tolerance) and sizes also influences the pattern of diversity and compositional change. Along with successional development, improvement of the understory environment, such as light availability through a decrease in stem density or gap formation, may promote the recruitment of new individuals or even new tree species.

\section{Demographic dynamics and forest development}

Demographic dynamics are necessary for promoting the understanding of environment-dependent ecological changes and responses (Kubota 1997; Needham et al. 


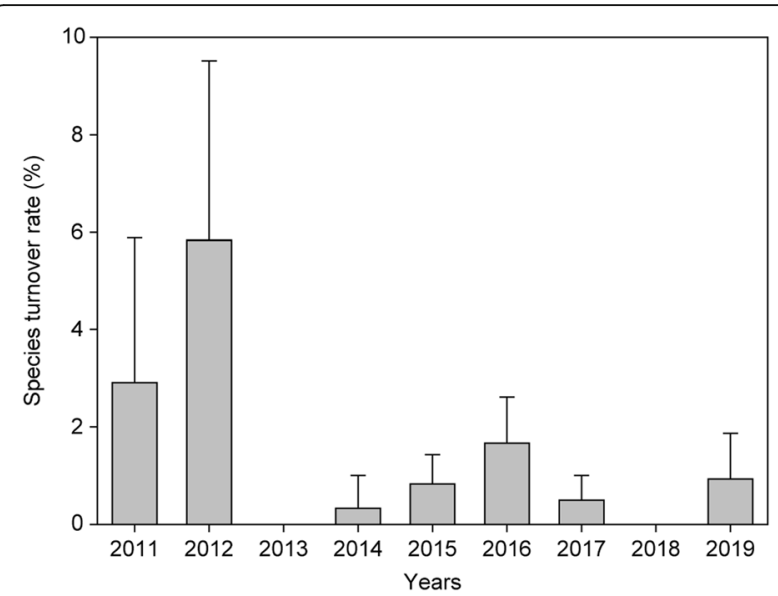

Fig. 10 Changes (2015-2019) in the species turnover rate in Albongbunji Basin/Ulleungdo. The species turnover rate in 2013 was 0 , and the calculation could not be made in 2018 due to data loss

2018; Brandl et al. 2019). During the observation period, mortality events in both shade tolerance (e.g., Tilia amurensis and Fagus engleriana) and shade intolerants (for example Acer pictum var. mono and Celtis jessoensis) of various sizes were recorded, which likely implies that the life-history strategy (level of shade tolerance) of a species exhibited minor effects on demographic rates (Fig. 7). An increase in shade-tolerant trees over the course of successional development has been reported in young European beech forests (Heiri et al. 2009). As an oceanic island, Ulleungdo was isolated for a very long period and species traits such as shade tolerance could be different from those of the same species on the mainland.

Trees with DBH ranging from 5 to $10 \mathrm{~cm}$ had the highest mortality rate, but the size distribution of the mortality rate also included large individuals $(\mathrm{DBH} \geq 20$ $\mathrm{cm})$. In general, in the stem exclusion stage of coniferous forests, most of the dying individuals are small trees, which reduces the deviation range in size distribution within the community (Franklin et al. 2002). However, in our field experiment in a young beech forest, individuals of various sizes died; thus, a decrease in tree size deviation was not observed (see Fig. 2c).

In our results obtained by observing the stem exclusion stage, the timing of the negative growth rate of the tree population coincided with the inflection point of the changing patterns in forest structure and function, decline in biomass and BHA growth rate, and decrease in stem density and species richness. More dramatic changes were observed in the decline in mean biomass growth rate compared with stem density so that changes in the carbon storage function of young beech forests are more sensitive to demographic dynamics. In general, biomass accumulation peaks in the early phase of forest development (canopy closure stage) (Cooper 1983). In an even-aged stand like our study site, the mortality of small or relatively large individuals contributes to reducing the community-level biomass accumulation rate (Ryan et al. 1997; Weiner and Thomas 2001). This process of reducing the biomass accumulation rate can reduce the carbon dioxide absorption capacity of forests, an important carbon sink. In this respect, further research is necessary to examine the correlation between forest functions such as aboveground net primary production and demographic rates such as tree death (Xu et al. 2012).

A gap in the canopy, no matter how small, caused by the death of a tree, stimulate the growth of adjacent individuals, generating horizontal heterogeneity. In our last measurements, large individuals' stem deaths also resulted in a large forest gap. These gap formations of various sizes and the resulting increase in spatial complexity have been determined to be important factors in post-maturation forest dynamics (Franklin and Van Pelt 2004), but their role has not yet been observed in a relatively young forest, like our study site. Our results are in accordance with those of studies on the development of temperate rainforests of evergreen conifers in North America (Lutz and Halpern 2006). The occurrence of a forest gap in a young forest also leads to changes in the surface environment, promoting the development of understory vegetation, and the recruitment of individuals in particular; large forest gaps may also reverse succession. The improvement of the successional perspective highlights the importance of detailed records of ecological succession.

Interestingly, in the first 5 years of the observation period, no stem death was observed, and multiple species died around the same time. Moreover, after the intersection of the recruitment rate and mortality rate, the recruitment rate remained near zero. It is difficult to infer the background of the concurrent occurrence of stem deaths. It may be an accidental event resulting from a natural process, and it may have been caused by the time lag effects of droughts in 2013 and 2014.

\section{Increased stochasticity and forest development}

The heavy rain-induced soil deposition (i.e., disturbance), the consequent stem deaths, and the generation of forest gaps resulted in the reduction of the dominant deterministic ecological processes such as resource competition and suppression, and contributed to the increase in uncertainty in the forest development process. During the observation period, the post-2015 deaths of trees of various sizes (including canopy trees) contributed to density reduction, and the stem density level in 2019 was the same as that of the initial measurement. It is 
worth noting that the heavy rain-induced continuous soil deposition in a part of the study site $(\leq 30 \%$ of the entire survey plot) that occurred since 2017 and the generation of a large forest gap caused by the death of Prunus takesimensis Nakai (Supplementary File 2) may have hampered the growth of existing individuals and settlement of new trees (Jung et al. in review). Furthermore, immediate or delayed effects due to continuous disturbance and occurrence of forest gaps of various sizes not only contributed to the stem mortality rate but also formed heterogeneous spaces by creating habitats for early succession within the quadrat. These ecological events contributed to an increase in the stochastic processes in the process of community development (Figs. 6 and 7). In forests, suppression accounts for the majority of individual deaths, which is mainly associated with the death of small-sized individuals (Oliver 1981; Franklin et al. 2002). Through the midterm observation, the stochastic processes increased the uncertainty in the progress of tree community development. Continuous observation of the study site would provide information on changes in the relative importance of these important ecological processes.

Our study in Albongbunji Basin/Ulleungdo was small on a spatial scale ( $0.5 \mathrm{ha})$, but through constant monitoring and recording of the development process of a Fagus engleriana-dominated tree community over a period of 11 years, we could produce observation-based data on midterm dynamics of demographic rates as well as structural and functional developments. Except for studies on the characteristics of species composition (i.e., phytosociological studies), research on the East Asian temperate zone forests dominated by Fagus engleriana was mainly focused on the gap regeneration process (Nakashizuka and Numata 1982; Shimano 2006; Yu et al. 2009; Zhang et al. 2017), and there are hardly any studies investigating secondary succession in young beech forests. Out study, conducted for 11 years in the stem exclusion stage, yielded records of important processes (e.g., timing of forest gap formation and increase in uncertainties of vegetation succession) helpful in improving the existing forest succession models along with general forest development patterns (e.g., sigmoidal development of biomass). Unlike our middle-stage level study, the spacefor-time research approach that connects different seral stages allows for the examination of multiple ecological time periods but has a limitation on its usefulness when a detailed explanation of the changing processes is required (Umeki and Kikuzawa 1999).

The limitation of our study is the lack of measurements of important succession-related environmental factors, such as soil properties of the study site. However, we constantly recorded the mineral soil exposure rate on the forest floor, which was helpful in understanding the backgrounds for the stochastic soil deposition events and changes in forest demographic rates (mortality rate and causes of stem death).

\section{Implications}

We elucidated the minute details of the middle-stage development dynamics of a Fagus engleriana-dominated young beech forest in the process of regrowth after the grazing ban. For ecologists and managers, understanding the ecosystem, habitat impact, and regrowth process after a large-scale disturbance such as agriculture or fire is very important, given that recent disturbance regimes and scales, such as frequent large-scale fires and rapid increases in land use for agricultural activities, have large effects on biodiversity and on ecological services such as carbon storage. In particular, it is necessary for managers to understand the processes and mechanisms by which habitats recover after a disturbance, and to efficiently manage the constantly changing conditions of natural resources by acquiring accurate information.

The successional dynamics of plant communities are affected mainly by two ecological processes: deterministic and stochastic processes (Måren et al. 2018). Our observation of the middle-stage forest development dynamics determined that the deterministic processes were predominant and that uncertainties of forest development increased under unexpected disturbance. The stochastic perspective highlights the role of species dispersal limitations and stochastic demographics in community assembly (Liu et al. 2018). However, as demonstrated by our results, changes induced by successional dynamics are the result of the complex interplay between disturbances and the events leading to forest gap occurrence, resource competition between upper story trees and understory vegetation, or suppression (Franklin et al. 2002). It can be expected that the relative importance of stochastic or deterministic processes will continue to change as forest development proceeds to other major stages that are associated with specific developmental processes and characteristic patterns, such as the increasing biomass at early successional stages, the asymptotic pattern of biomass accumulation at the mid-successional stage, density-dependent tree mortality in early succession, and density-independent tree death after the mid-successional stage.

\section{Conclusions}

We exhibited the details of the middle-stage development dynamics of a Fagus engleriana-dominated young beech forest in the process of regrowth after the grazing ban. There is a dramatic shift between the recruitment and mortality rates in the stem exclusion stage, and that disturbance increases the uncertainty in forest development increases by stochastic soil deposition disturbance. 
Gap formation events, known as the representative latesuccessional process, were recorded in a young beech forest and consequent horizontal divergence was followed. During the observation period, limited changes were observed in species richness and species turnover rate. These minor changes in species composition are likely linked to regional species pool and the limited role of the life-history strategy of species such as shade tolerance and habitat affinity. Our midterm records of ecological succession exhibited detailed demographic dynamics and contributed to the improvement of an ecological perspective in the stem exclusion stage.

\section{Methods}

\section{Study site}

The study was conducted in the Albongbunji Basin on Ulleungdo $\left(37^{\circ} 14^{\prime}-33^{\prime} \mathrm{N}, \quad 130^{\circ} 47^{\prime}-131^{\circ} 52^{\prime} \mathrm{E}\right)$, an oceanic island in the East Sea (Fig. 9). Ulleungdo is a quaternary volcanic island about $200 \mathrm{~km}$ east of the Korean Peninsula (Ministry of Land Infrastructure and Transport 2016). This islet $\left(72.9 \mathrm{~km}^{2}\right)$ has been inhabited since the Bronze Age ( 3000 years ago) (Rii 2012). From 1981 to 2010, it has a mild climate with an average annual temperature of $12.4^{\circ} \mathrm{C}$, and its annual average precipitation of $1383.4 \mathrm{~mm}$ is evenly distributed throughout the year (Korea Meteorological Administration 2011). Together with Jejudo Island, it belongs to the humid maritime floristic zone of South Korea (Jung and Cho 2020). Kira's coldness index in Ulleungdo ranges from -42.8 to -0.6 (Cho et al. 2020).

Among the plains within the Nari Caldera, the Naribunji Basin is mainly used for wild vegetable cultivation, and the Albongbunji Basin is covered with grassland or young mixed deciduous broad-leaved forest in the abandoned pasture. The Albongbunji Basin has fertile volcanic ash soil (Park 1997). The Albongbunji Basin was used for grazing cows and goats for some time, but cattle raising is prohibited now and only small-scale crop farming (e.g., corn) was observed. In places in the Albongbunji Basin, where agricultural activities are prohibited, farmland has returned to secondary forests or to Miscanthus sinensis and Fallopia sachalinensis co-dominated grasslands. Forests in the Albongbunji Basin are either Fagus engleriana-dominated forests or mixed forests, consisting of deciduous broad-leaved trees such as Celtis jessoensis, Acer pictum var. mono, Sorbus ulleungensis, and Cornus controversa, with evergreen conifers, such as Tsuga ulleungensis) and Taxus cuspidata, growing in the subtree layer (Korea National Arboretum 2019).

During the survey period (2009-2019), there were no significant temperature fluctuations on Ulleungdo, but there was localized heavy rain $(\geq 400 \mathrm{~mm})$ capable of producing mudslides that occurred four times between 2016 and 2019 (Korea Meteorological Administration 2020). Sloped areas where the Albongbunji Basin and Nari Caldera meet were affected by soil deposition from the surrounding slopes rather than by floods from heavy rain. We assessed the extent of soil deposition in the 2019 measurements. The average difference between the initial tag height $(130 \mathrm{~cm})$ and the height from the floor to the tag was $22.2 \pm 26.0$ $\mathrm{cm}(n=538)$. In extreme cases, over $50 \mathrm{~cm}$ of soil deposition was observed (Supplementary File 2). Although no instantaneous large-scale decay of constituent species (death or leaf drop) was observed despite continuous soil deposition under the well-drained soil conditions, adverse effects on the recruitment and mortality processes and some time lag effects are expected to occur over time.

From July to September 2018 in Ulleungdo, a geometrid moth outbreak was observed, and attacked trees were fully defoliated (Cho et al. 2019). This outbreak of geometrid moths began in high-altitude areas on Ulleungdo and gradually expanded to lower areas. By the time the outbreak spread to the Albongbunji Basin, its force was fading away, and larvae feeding on leaves were hardly observed during on-site measurements.

\section{Survey and analysis}

For long-term observations of the deciduous broadleaved forest, a survey plot was installed in June 2009 at $20 \mathrm{~m}$ distance from an arroyo (a dry creek that flows only when it rains) at the angle of 90 degrees to its flowing direction. This rectangular plot $(0.2 \mathrm{ha} ; 100 \mathrm{~m} \times 20$ $\mathrm{m})$ was subdivided into 20 quadrats $\left(100 \mathrm{~m}^{2} ; 10 \mathrm{~m} \times 10\right.$ m). From 2009 (measurement initiation) to 2012, we used these 20 quadrats and expanded the plot to a size of 0.5 ha $(100 \mathrm{~m} \times 50 \mathrm{~m})$ in 2013 by adding a 0.3 ha stripe $(100 \mathrm{~m} \times 30 \mathrm{~m}$, subdivided into 30 quadrats of 10 $\mathrm{m} \times 10 \mathrm{~m})$ to the initial plot. That is, the survey was conducted in 20 quadrats from 2009 to 2012 and 50 quadrats from 2013 to 2019. In the center of each quadrat installed in 2009, we installed three micro-quadrats $\left(3 \mathrm{~m}^{2}, 1 \mathrm{~m}^{2}\right.$ each) for understory vegetation surveys. When measuring the understory vegetation, we recorded the mineral soil exposure rate (\%) of the forest floor as the degree of disturbance of understory vegetation. The mineral soil exposure rate was excluded from the measurements in 2010, 2013, and 2014. Additionally, tree communities were not visited in 2010, and 2018 was excluded from the analysis because the measurement data were lost.

We performed species identification and measured the diameter at breast height $(\mathrm{DBH} ; \mathrm{BH}=120 \mathrm{~cm})$ of each tree $(\mathrm{DBH} \geq 2.5 \mathrm{~cm})$, and recorded one of the seven 
causes of death: suppression, mechanical damage incurred by an upper- or mid-layer tree, slope failure or soil deposition, wind, pathogen, animal damage, and unknown (no clear evidence of any of the six causes). The major tree species can be divided into shade tolerance (Tilia amurensis and Fagus engleriana) and shade intolerance (Acer pictum var. mono, Celtis jessoensis, Prunus takesimensis, and Cornus controversa) preferring disturbed sunny habitats for regeneration. However, we did not perform community structure analysis reflecting habitat preference because of low diversity and limited population size.

We measured the initial community structure and the environment in 2009. For age structure analysis, we extracted 264 growth rings from trees with a stem diameter of at least $5 \mathrm{~cm}$ at a height of $30 \mathrm{~cm}$ from the floor. For age determinations, we extracted cores using an increment borer (Haglof increment borer, Sweden) and estimated the age using CORIM Maxi (USA). For canopy openness measurements, we used a fisheye lens to capture the canopy image from the center of the quadrat (Nikon D700, Lens: Sigma 4.5 $\mathrm{mm}$; F2.8 EX DC CIRCULAR FISHEYE) at $1 \mathrm{~m}$ height. The collected images were analyzed using Gap Light Analyzer 2.0 (Frazer et al. 1999).

Changes in forest structure were estimated by measuring the quadrat-level mean stem density (stems ha ${ }^{-1}$ ) and mean breast height area (BHA) $\left(\mathrm{m}^{2} \mathrm{ha}^{-1}\right)$. We verified the tree species of each stem with a DBH of at least $2.5 \mathrm{~cm}$ (breast height: $120 \mathrm{~cm}$ ) in each quadrat from 2009 to 2019 and measured the diameter using a diameter tape (Shinill Science, South Korea). We analyzed and visualized the changes in the size distribution (DBH and biomass) of the constituent species using the distribution function (Lima et al. 2016) and fitdistrplus, an R package for fitting distributions (Delignette-Muller and Dutang 2015). The Weibull function that commonly used diameter-frequency distribution function in Ecology was applied (Chen 2004);

$$
\begin{aligned}
f(\mathrm{x}) & =c / b[(x-a) / b]^{c-1} \exp \left\{-[(x-a) / b]^{c}\right\} ; x \geq \mathrm{a}, b \\
& >0, c>0
\end{aligned}
$$

where $a$ is the location parameter, $b$ is the scale parameter, and $c$ is the shape parameter. In a diameter (or biomass) class context, the location parameter $a$ can be interpreted as the smallest $d / d_{a}$ (i.e., 0 ), which reduces the Weibull function to two parameters, scale, and shape. In the Weibull function, the lower the value of a shape parameter, with the area fixed, the closer to the shape of the right-skewed distribution, and the higher the value, the closer to the shape of the symmetric distribution. Regarding the scale parameter, the higher the value, with the area fixed, the longer the periphery of the size distribution and the more reduced the height. The analysis results are presented as the value and standard deviation of each parameter.

Changes in forest functions were estimated by analyzing changes in the living biomass of trees and species diversity (richness). The mean biomass (ton $\mathrm{ha}^{-1}$ ) and species diversity were calculated at the quadrat level. We used the existing allometric equation for the species or genus to calculate the biomass of each tree species (Table 1).

For changes in species composition, the species turnover rate was calculated at the quadrat level and the mean turnover rate was presented. As mentioned above, the changed values in the initially installed 20 quadrats were used from 2009 to 2013 and the changed values in all 50 quadrats were used thereafter. The species turnover rate in 2011 was obtained by multiplying $1 / t$ to convert it to the annual level, where $t$ denotes the measurement interval. The species turnover rate was

\begin{tabular}{|c|c|c|c|}
\hline Species & Equation & Reference & Range \\
\hline Acer pictum subsp. mono & $Y=1.9394^{*} \mathrm{D}^{\wedge} 1.6483$ & Luo et al. 2018 & $1-45 \mathrm{~cm}$ \\
\hline Acer takesimense & $A G B=0.1381^{*} D^{\wedge} 2.3771$ & Li et al. 2017 & None \\
\hline Celtis jessoensis & $y=0.2051^{*} D^{\wedge} 2.4354$ & Luo et al. 2018 & $2.0-12.7 \mathrm{~cm}$ \\
\hline Cornus controversa & $\ln (A G B)=-2.2118+2.4133^{*} \ln (D)$ & Chojnacky et al. 2014 & $3-64 \mathrm{~cm}$ \\
\hline Fagus engleriana & $y=0.2460^{*} \mathrm{D}^{\wedge} 2.0800+0.0074^{*} \mathrm{D}^{\wedge} 2.84+0.000546^{*} \mathrm{D}^{\wedge} 3.2+0.0828^{*} \mathrm{D}^{\wedge} 2.22$ & Luo et al. 2018 & $2-35.5 \mathrm{~cm}$ \\
\hline Phellodendron amurense & $A G B=9.5350^{*} D^{\wedge} 0.7241+0.0322^{*} D^{\wedge} 2.2785+0.0222^{*} D^{\wedge} 2.0330$ & Luo et al. 2018 & $7.1-21.4 \mathrm{~cm}$ \\
\hline Prunus takesimensis & $A G B=0.1381 * D \wedge 2.3771$ & Li et al. 2017 & None \\
\hline sorbus ulleungensis & $\ln (A G B)=-2.2118+2.4133^{*} \ln (D)$ & Chojnacky et al. 2014 & $3-64 \mathrm{~cm}$ \\
\hline Styrax obassia & $A G B=0.1381 * D^{\wedge} 2.3771$ & Li et al. 2017 & None \\
\hline Taxus cuspidata & $\ln (A G B)=-2.4623+2.4852^{*} \ln (D)$ & Chojnacky et al. 2014 & $3-215 \mathrm{~cm}$ \\
\hline Tilia insularis & $Y=0.2220^{*} \mathrm{D} \wedge 2.2550$ & Luo et al. 2018 & $7.0-42.2 \mathrm{~cm}$ \\
\hline Ulmus laciniata & $\ln (A G B)=-2.2118+2.4133^{*} \ln (D)$ & Chojnacky et al. 2014 & $3-64 \mathrm{~cm}$ \\
\hline
\end{tabular}

Table 1 Allometric equations used to calculate tree species biomass at Ulleungdo 
calculated using the $\mathrm{R}$ package codyn as shown below (Hallett et al. 2016).

Turnover rate $=($ Number of species gained + Number of species lost)/Total number of species at both time points

We calculated the dynamics in demographic rates at the plot level taking into account their relatively small measurement scales. We calculated mortality rate $(M)$, and recruitment rate $(R)$, and tree population growth rate $(\lambda)$ (Sheil and May 1996; Condit et al. 1999; Lima et al. 2016) with the following equations:

$$
M=100\left[1-\left(N_{t} / N_{0}\right)^{1 / t}\right]
$$

where $N_{O}$ is the number of the stems alive at the time of the previous measurement, $N_{t}$ is the number of the stems alive at the time of present measurement among the stems alive at the time of the previous measurement, and $t$ is the measurement interval (year).

$$
R=100\left[1-\left(1-\left(N_{\text {new }} / N_{O}\right)^{1 / t}\right)\right]
$$

where $N_{O}$ is the number of the stems alive at the time of the previous measurement, $N_{\text {new }}$ is the number of stems added at the present measurement, and $t$ is the measurement interval (year).

$$
\lambda=(R-M) /(1 / \mathrm{t})
$$

where $R, M$, and $\lambda$ denote the recruitment rate, mortality rate, and population growth rate, respectively. In order to rule out the influence of plot expansion when analyzing the demographic rates, we used only the values obtained from the initially installed 20 quadrats until 2013 and all measured values thereafter. The correlation between the recruitment and mortality rates was analyzed using the Pearson correlation (Legendre and Legendre 2012). Statistical analysis was performed using $R$ studio (RStudio Team 2020).

We used the rate of tree mortality to assess the relative importance of ecological processes (deterministic and stochastic) to tree community development as follows: suppression and animal damage as deterministic processes and mechanical damage, slope failure/soil deposition, wind, and pathogens as stochastic processes. Species identifications were made based on Lee (Lee 2014), Kim and Kim (Kim and Kim 2018), and, for scientific names, the Korea Plant Names Index (Korea National Arboretum 2017).

\section{Supplementary Information}

The online version contains supplementary material available at https://doi. org/10.1186/s41610-020-00170-x.

Additional file 1: Supplementary Figure S1. The frequency

distribution histograms of the diameter class (top) and biomass class (bottom) measured in the tree communities in the Albongbunji Basin over a period of 11 years.

Additional file 2: Plate 1. The survey plot was installed in Albongbunji Basin, Ulleungdo, taken in 2019 (left). This young beech forest (approximately 60 years old) is in the stem exclusion stage of forest development. Broken stems of the canopy species Prunus takesimensis (Ulleungdo cherry, endemic species) and Acer pictum var. mono originated from gap events induced by stochastic disturbances (wind and mechanical damage), which were observed at an earlier stage than in traditional development models. The forest floor of the survey plot is continuously changing in terms of micro-level geomorphology due to soil deposition caused by heavy rains. In part of the survey plot, soil deposition has been taking place since 2016 (right). The red arrow on the picture is the spot where the number tag was attached at the breast height $(120 \mathrm{~cm})$ in 2009 .

\section{Abbreviations}

DBH: Diameter in breast height; BHA: Breast height area

\section{Acknowledgements}

This research began in 2009 by the Kyungpook National University Department of Ecology and Environmental Systems. Since 2010, this research has been carried out jointly by the Plant Ecology Laboratory of the Korea National Arboretum and the Korean Institute of Vegetation Science. We would like to sincerely thank all of the colleagues who participated in the field experiments.

\section{Authors' contributions}

CYC and BKH designed the study, CYC, SHS, KJS, KHG, and JSH carried out field sampling and performed the analysis, and CYC wrote the manuscript. $\mathrm{BKH}$ reviewed the manuscript. The author(s) read and approved the final manuscript.

\section{Funding}

This research was supported by the Research Program (KNA1-2-17, 13-3, KNA1-2-26, 16-4 and KNA1-2-32, 18-3) of the Korea National Arboretum. The funding body had no role in the design of the study or collection, analysis, and interpretation of data or in writing the manuscript.

\section{Availability of data and materials}

The datasets used and/or analysed during the current study are available from the corresponding author on reasonable request.

Ethics approval and consent to participate

Not applicable.

Consent for publication.

Not applicable

\section{Competing interest}

The authors declare that they have no competing interests.

\section{Author details}

${ }^{1}$ Conservation Center for Gwangneung Forest, Korea National Arboretum, Pocheon 11186, South Korea. ${ }^{2}$ Department of Forest Resources, Graduate School of Kookmin University, Seoul 02707, South Korea. ${ }^{3}$ Korean Institute of Vegetation Science, Daegu 41001, South Korea. ${ }^{4}$ School of Ecology \& Environmental System, Kyungpook National University, Sangju 37224, South Korea. 
Received: 25 September 2020 Accepted: 9 November 2020

Published online: 23 November 2020

\section{References}

Barnes B, Zak D, Denton S, Spurr S. Forest ecology. New York: Wiley; 1998

Brandl SJ, Tornabene L, Goatley CHR, Casey JM, Morais RA, Côté IM, et al. Demographic dynamics of the smallest marine vertebrates fuel coral reef ecosystem functioning. Science. 2019;364:1189-92.

Cao K-F, Peters R, Oldeman RAA. Climatic range and distribution of Chinese Fagus species. J Veg Sci. 1995;6:317-24.

Chase JM, Myers JA. Disentangling the importance of ecological niches from stochastic processes across scales. Philos Trans R Soc Lond B Biol Sci. 2011; 366:2351-63.

Chen $\mathrm{W}$. Tree size distribution functions of four boreal forest types for biomass mapping. For Sci. 2004:50:436-49.

Cheon Kl, Chun JH, Yang HM, Lim JH, Shin JH. Changes of understory vegetation structure for 10 years in long-term ecological research site at Mt. Gyebang. J Korean Soc For Sci. 2014;103:1-11.

Cho HJ, Bae KH, Lee BC, Hong SC. Ecological studies on the vegetation characteristics of the virgin forests of Songin-bong in Ulreung Island, Korea. J Korean For Soc. 1993;82:139-51.

Cho YC, Kim H-G, Kim JS, Lee H, Jung SH, Lee DH, et al. 2019 Annual report on Gwangneung forest and experimental forest. Seoul: Sumeungil; 2020

Cho YC, Kim H-G, Kim JS, Lee H, Lee DH, Bae KH, et al. 2018 Annual report on Gwangneung forest and experimental forest. Seoul: Sumeungil; 2019.

Chun J-H, Lee C-B. Temporal changes in species, phylogenetic, and functional diversity of temperate tree communities: Insights from assembly patterns. Front Plant Sci. 2019:10:294

Condit R. Research in large, long-term tropical forest plots. Trends Ecol Evol. 1995;10:18-22.

Condit R, Ashton PS, Manokaran N, LaFrankie JV, Hubbell SP, Foster RB. Dynamics of the forest communities at Pasoh and Barro Colorado: comparing two 50ha plots. Philos Trans R Soc Lond B Biol Sci. 1999:354:1739-48.

Coomes DA, Allen RB. Mortality and tree-size distributions in natural mixed-age forests. J Ecol. 2007;95:27-40.

Cooper CF. Carbon storage in managed forests. Can J For Res. 1983;13:155-66.

Delignette-Muller ML, Dutang C. Fitdistrplus: An R package for fitting distributions. J Stat Softw. 2015;64:34

Ediriweera S, Bandara C, Woodbury DJ, Mi X, Gunatilleke IAUN, Gunatilleke CVS, et al. Changes in tree structure, composition, and diversity of a mixeddipterocarp rainforest over a 40-year period. Forest Ecol Manag. 2020;458 117764.

Fang J, Lechowicz MJ. Climatic limits for the present distribution of beech (Fagus L.) species in the world. J Biogeogr. 2006;33:1804-19.

Franklin JF, Spies TA, Pelt RV, Carey AB, Thornburgh DA, Berg DR, et al. Disturbances and structural development of natural forest ecosystems with silvicultural implications, using Douglas-fir forests as an example. Forest Eco Manag. 2002:155:399-423.

Franklin JF, Van Pelt R. Spatial aspects of structural complexity in old-growth forests. J For. 2004:102:22-8.

Frazer GW, Canham CD, Lertzman KP. Gap Light Analyzer (GLA), Version 2.0: Imaging software to extract canopy structure and gap light transmission indices from true-colour fisheye photographs, users manual and program documentation. Simon Fraser University, Burnaby, British Columbia, and the Institute of Ecosystem Studies. New York: Millbrook; 1999.

Gitzen RA, Cooper AB, Millspaugh JJ, Licht DS. Design and analysis of long-term ecological monitoring studies. Cambridge: Cambridge University Press; 2012.

Glatthorn J, Feldmann E, Tabaku V, Leuschner C, Meyer P. Classifying development stages of primeval European beech forests: is clustering a useful tool? BMC Ecol. 2018;18:47.

Guo K, Werger MJA. Effect of prevailing monsoons on the distribution of beeches in continental East Asia. Forest Ecol Manag. 2010;259:2197-203.

Hallett LM, Jones SK, MacDonald AAM, Jones MB, Flynn DFB, Ripplinger J, et al. codyn: An r package of community dynamics metrics. Methods Ecol Evol. 2016;7:1146-51.

Halpern CB, Lutz JA. Canopy closure exerts weak controls on understory dynamics: a 30-year study of overstory-understory interactions. Ecol Monogr. 2013:83:221-37.

Heiri C, Wolf A, Rohrer L, Bugmann H. Forty years of natural dynamics in Swiss beech forests: structure, composition, and the influence of former management. Ecol Appl. 2009;19:1920-34.
Hobbie JE. Scientific accomplishments of the Long Term Ecological Research program: an introduction. BioScience. 2003:53:17-20.

Hubbell SP. The unified neutral theory of biodiversity and biogeography (MPB32). Princeton: Princeton University Press; 2001

Jeong KJ. Geographical information in The Diary of Inspection on Ulleungdo by Royal Inspector Rii Kyu Won. Geogr Res. 2006;31:27-40.

Jung SH, Cho YC. Redefining floristic zones on the Korean Peninsula using high-resolution georeferenced specimen data and self-organizing maps (SOMs). Authorea. 2020. doi: https://doi.org/10.22541/au.159301770. 06491953.

Kim JW. The phytosociology of forest vegetation on Ulreung-do. Phytocoenologia. 1988;16:259-81.

Kim SD, Kimura M, Yim YJ. Phytosociological studies on the beech (Fagus nultinervis Nakai) forest and the pine (Pinus parviflora S. et Z.) forest of Ulreung island, Korea. Korean J Botany. 1986;29:53-65.

Kim TY, Kim JS. Woody plants of Korean Peninsula. Dolbegae: Paju; 2018.

Korea Meteorological Administration. Climatological normals of Korea. Seoul: Korea Meteorological Administration; 2011.

Korea Meteorological Administration. 2019 Abnormal climate report. Seoul: Korea Meteorological Administration; 2020.

Korea National Arboretum. Checklist of vascular plants in Korea. Pocheon: Korea National Arboretum; 2017

Korea National Arboretum. Annual report on Gwangneung forest and experimental forest. Seoul: Sumeungil; 2019.

Kubota Y. Demographic traits of understory trees and population dynamics of a Picea-Abies forest in Taisetsuzan National Park, northern Japan. Ecol Res. 1997; 12:1-9.

Lee DH. Identification of Korean woody plants. Seoul: Ibirak; 2014.

Lee $\mathrm{JH}$, Cho HJ, Hur TC. Spatial distribution and vegetation-environment relationship of forest vegetation in Ulleung Island, Korea. J Ecol Field Biol. 2006;29:521-9

Legendre P, Legendre LF. Numerical ecology. Boston: Elsevier; 2012.

Lima RA, Muller-Landau HC, Prado PI, Condit R. How do size distributions relate to concurrently measured demographic rates? Evidence from over 150 tree species in Panama. J Trop Ecol. 2016;32:179-92.

Liu B, Chen HYH, Yang J. Understory community assembly following wildfire in boreal forests: Shift from stochasticity to competitive exclusion and environmental filtering. Front Plant Sci. 2018;9:1854.

Lutz JA, Halpern CB. Tree mortality during early forest development: a long-term study of rates, causes, and consequences. Ecol Monogr. 2006;76:257-75.

Måren IE, Kapfer J, Aarrestad PA, Grytnes J-A, Vandvik V. Changing contributions of stochastic and deterministic processes in community assembly over a successional gradient. Ecology. 2018;99:148-57.

Ministry of Land Infrastructure and Transport. The national atlas of Korea II. Suwon: National Geography Information Institute; 2016.

Moridi M, Sefidi K, Etemad V. Stand characteristics of mixed oriental beech (Fagus orientalis Lipsky) stands in the stem exclusion phase, northern Iran. Eur J For Res. 2015;134:693-703.

Nakashizuka T, Numata M. Regeneration process of climax beech forests. I. Structure of a beech forest with the undergrowth of Sasa. Japanese J Ecol. 1982:32:57-67.

Needham J, Merow C, Chang-Yang CH, Caswell H, McMahon SM. Inferring forest fate from demographic data: from vital rates to population dynamic models. Proc Biol Sci. 2018;20172050.

Noss RF. Indicators for monitoring biodiversity: a hierarchical approach. Conserv Biol. 1990:4:355-64

Oliver CD. Forest development in North America following major disturbances. Forest Ecol Manag. 1981;3:153-68.

Park HD. The physical geography of Ulreungdo Island. Geogr Res. 1997;31:27-40.

Peters R. Ecology of beech forests in the northern hemisphere. Wageningen: Landbouwuniversiteit; 1992

Phillips OL, Hall P, Gentry AH, Sawyer SA, Vásquez R. Dynamics and species richness of tropical rain forests. P Proc Natl Acad Sci U S A. 1994;91:2805-9.

Rii HU. Geographical landscape of Ulleung Island in the re-settlement period. J Assoc Korean Photo-Geogr. 2012;22:13-23.

RStudio Team. RStudio: Integrated development for R. Boston: RStudio, PBC; 2020.

Ryan M, Binkley D, Fownes JH. Age-related decline in forest productivity: pattern and process. Adv Ecol Res. 1997;27:213-62.

Sergeant CJ, Moynahan BJ, Johnson WF. Practical advice for implementing longterm ecosystem monitoring. J Appl Ecol. 2012;49:969-73. 
Sheil D, May RM. Mortality and recruitment rate evaluations in heterogeneous tropical forests. J Ecol. 1996;84:91-100.

Shimano K. Differences in beech (Fagus crenata) regeneration between two types of Japanese beech forest and along a snow gradient. Ecol Res. 2006;21: 651-63.

Spellerberg IF. Monitoring ecological change. Cambridge: Cambridge University Press; 2005

Stephenson NL, Mantgem PJ. Forest turnover rates follow global and regional patterns of productivity. Ecol Lett. 2005;8:524-31.

Umeki K, Kikuzawa K. Long-term growth dynamics of natural forests in Hokkaido, northern Japan. J Veg Sci. 1999;10:815-24.

Vellend M. Conceptual synthesis in community ecology. Q Rev Biol. 2010;85:183206.

Weiner J, Thomas SC. The nature of tree growth and the "age-related decline in forest productivity". Oikos. 2001;94:374-6.

Xu C-Y, Turnbull MH, Tissue DT, Lewis JD, Carson R, Schuster WSF, et al. Agerelated decline of stand biomass accumulation is primarily due to mortality and not to reduction in NPP associated with individual tree physiology, tree growth or stand structure in a Quercus-dominated forest. J Ecol. 2012;100: 428-40.

Yu S, Wang R, Liu M, Yang S-Z, Luo Y, Chen X-Y. Species composition and sprouting regeneration of Fagus engleriana community in Tian-mushan Mountain. Chinese J Ecol. 2009;28:182-7.

Zhang Q, Jiang M, Chen F. Canopy recruitment in the beech (Fagus engleriana) forest of Mt. Shennongjia, Central China. J For Res. 2017;12:63-7.

\section{Publisher's Note}

Springer Nature remains neutral with regard to jurisdictional claims in published maps and institutional affiliations.

Ready to submit your research? Choose BMC and benefit from:

- fast, convenient online submission

- thorough peer review by experienced researchers in your field

- rapid publication on acceptance

- support for research data, including large and complex data types

- gold Open Access which fosters wider collaboration and increased citations

- maximum visibility for your research: over $100 \mathrm{M}$ website views per year

At $\mathrm{BMC}$, research is always in progress.

Learn more biomedcentral.com/submissions 